\title{
Time-Division Multiplexed Pulsed Charging of Modular Pb-acid Battery Storage
}

\author{
S. D. Das \\ Electronics and Communication Engineering, BIEMS, Kolkata, India
}

\begin{abstract}
Electrical storage system comprising of single storage unit is often heavy, especially using lead acid batteries. One way to deal with this issue is to use number of small storage units where each storage unit is capable of driving a load for a minimum duration of time. This concept of electrical storage system is modular storage system. Apart from advantages of light weight, modular systems would require lower charging power, making it energy efficient system. Modular storage system could be used for stand alone power system applications such as for home lighting, shop lighting, unmanned aerial vehicles and robotics. Such storage systems should lower the cost of solar panel in off-grid solar photovoltaic applications. This paper introduces the concept of modular storage system and demonstrates Pb-acid based modular storage system along with its charging using time-division multiplexing method. Time-division multiplexing method utilizes pulsed charging method which reduces the charging power requirement and charging time of the divided system.
\end{abstract}

Keywords: TDM, PB-acid battery, modular storage, pulsed charging, charging time

\section{INTRODUCTION}

Stand alone electrical storage systems are required for many applications. One of the very important area is lighting of shops and houses were grid-electricity is yet to reach. Solar power is a potential solution to these areas. However, off-grid solar products are still at relative disadvantage due to their high initial investment and such solar products are not easily accessible through local electrical shops. In general, electrical storage systems can be made out of single or multiple electrical storage units depending on the power requirement of the electrical load of particular application and commercially available capacity specifications of storage units. Such storage systems are often heavy and slow charging depending upon technology of storage units in use. These disadvantages are particularly true for low cost systems. Fast charging systems are costly due to higher power requirements $[1,2]$ and charging time is dependent on limitation of storage unit technology. For off-grid solar photovoltaic (SPV) systems, high charging power technique to reduce charging time implies increasing number of SPV cells and hence incrementing system cost.

Table 1. Comparison of technical parameters of different types of supercapacitor and batteries technologies.

\begin{tabular}{|c|c|c|c|c|}
\hline \multirow[b]{2}{*}{ Parameters } & \multicolumn{2}{|c|}{ Supercapacitors } & \multicolumn{2}{|c|}{ Batteries } \\
\hline & EDLC & $\begin{array}{l}\text { Hybrid } \\
\text { (Li-ion) }\end{array}$ & Li-ion & Pb-Acid \\
\hline Temperature Range $\left({ }^{\circ} \mathrm{C}\right)$ & -20 to +70 & -20 to +70 & -20 to +60 & -40 to +27 \\
\hline Cell Voltage (V) & 1.2 to 3.3 & 2.2 to 4.2 & 2.5 to 4.2 & 1.8 to 2.1 \\
\hline Charge/discharge cycles & $10^{5}$ to $10^{6}$ & $10^{5}$ to $10^{6}$ & 500 to $10^{4}$ & 250 to $10^{3}$ \\
\hline Energy Density (Wh/Kg) & 1.5 to 3.9 & 10 to 15 & 100 to 265 & 35 to 40 \\
\hline Power density $(\mathrm{kWh} / \mathrm{Kg})$ & 2 to 10 & 3 to 14 & 0.3 to 1.5 & $\sim 0.04$ \\
\hline Self discharge time at $\mathrm{RT}^{*}$ & weeks & months & months & months \\
\hline Lifetime at RT* (Years) & 5 to 10 & 5 to 10 & 3 to 5 & 1.5 to 2 \\
\hline Charging Time (hr) & $\begin{array}{l}\text { seconds to } \\
\text { minutes }\end{array}$ & minutes & $\begin{array}{l}\text { minutes to } \\
\text { hours }\end{array}$ & hours \\
\hline
\end{tabular}

* RT- room temperature 


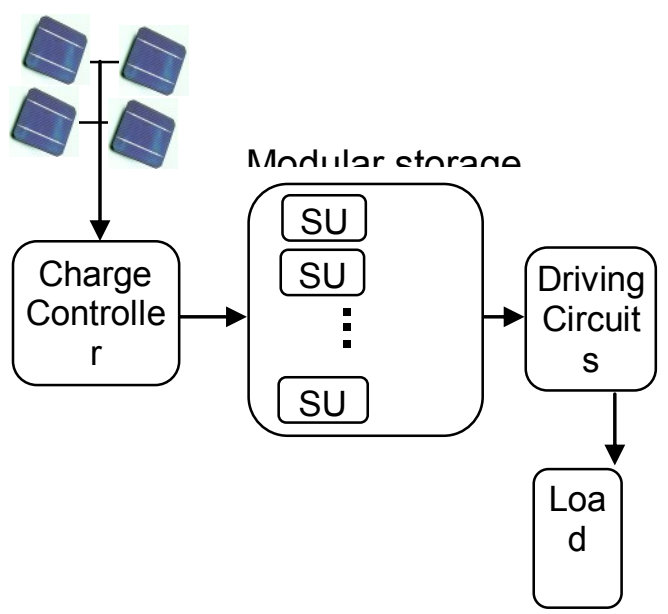

(a)

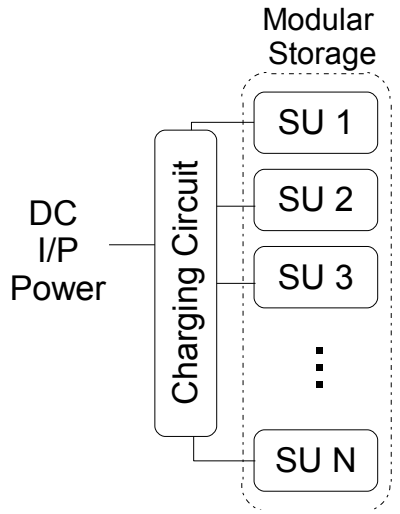

(b)

Fig. 2 (a) Schematic diagram of modular storage system using solar charging and (b) Schematic diagram of a general modular storage system with $\mathrm{N}$ storage units (SU) for use in other than solar applications.

The state of the art in solar products uses $\mathrm{Pb}$-acid batteries, since $\mathrm{Pb}$-acid battery technology is suitable for applications with larger power requirement and where lower gravimetric energy density is not a concern. Further, $\mathrm{Pb}$-acid battery technology dominate this market due to maturity of technology, recyclability and lower cost [3]. Alternative to Pb-acid battery is Li-ion batteries which has higher gravimetric energy density, longer life time and faster charging time [4]. Automotive industry has started to adopt this technology [5,6]; however due to higher cost, off-grid solar industry is yet to adopt Li-ion battery technology apart from automotive industry which do use solar charger for Li-ion batteries. Fast charging of batteries would provide ability to harness more total solar power per day. In terms of fast charging capability battery technology is not the state of the art. A supercapacitor can be charged in seconds or in minutes depending upon input power and capacitance value [7]. This is due to non-involvement of Faradaic reactions in supercapacitors [8]. Supercapacitors are thus becoming popular due to their many advantages over battery technology such as longer life time and faster charging time. A comparison chart of performance have been shown in Table 1 for different supercapacitor and battery technologies. Hindrance in adoption of supercapacitors for off-grid solar applications, apart from technological issues, is its cost. Thus cost reduction of supercapacitor should be one of the primary goal of such research.

In this paper, concept of modular storage will be introduced which could potentially bring down product cost and initial investment barrier for solar products. Potential advantages of such system will be highlighted and design issues of such systems will be presented for $\mathrm{Pb}$-acid battery. A brief discussion relating to adoption of supercapacitor for such system will also be presented.

\section{MODULAR STORAGE SYSTEM}

Two of the largest contributors towards large initial investment in any off-grid solar product corresponds to solar cell cost and cost of electrical storage. To counter these issues one could divide an electrical storage into smaller ones. Small electrical storage requires smaller charging power and hence at any given instance system will require less charging power. Thus number of solar cells required to charge the storage system will be less as compared to a single larger electrical storage. This will bring down the solar cell cost of the initial investment in off-grid solar systems. To further reduce the initial investment of a off-grid solar product one could design the system in such a way that each small capacity battery or storage unit of modular storage system should be able to drive a given load for a minimum duration of time. Such a system is modular storage system (Fig. 2(a)). By providing the system with one such storage unit initially along with opportunity to add such storage units later, initial investment can be spread over desired duration of time by consumer. Modular storage units are not only suitable for solar applications but the concept could easily be adopted for other application areas such as robotics, unmanned areal vehicles (UAV), UPS systems, electric automobiles and so on (Fig. 2(b)). For each of this application areas option of adding further storage units later would enhance range of operation or duration of operation. Further it will be shown in subsequent sections that modular storage systems are more energy efficient system than single large electrical storage system, which is a must for all future solar technologies [9]. 


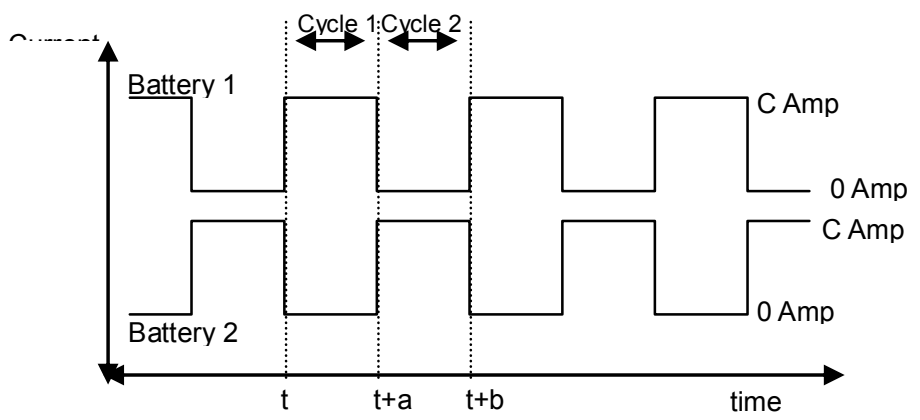

Fig. 4 Time-Division Multiplexed (TDM) scheme of charging of Pb-acid battery

\section{PB-ACID BASED MODULAR STORAGE SYSTEM}

Considering a system requires a $\mathrm{Pb}$-acid battery of $\mathrm{V}$ volts and $\mathrm{C}$ A-hr capacity. To convert it into a modular storage the system would require $\mathrm{N}$ number of storage units where each unit can have voltage specification of $\mathrm{V} / \mathrm{N}$ volts and $\mathrm{C} A-\mathrm{hr}$ capacity. The number $\mathrm{N}$ will be guided by specification of commercially available $\mathrm{Pb}$-acid battery. For example a $12 \mathrm{~V}, 1 \mathrm{~A}$-hr capacity battery can be replaced by $\mathrm{N}=2,6 \mathrm{~V}, 1 \mathrm{~A}-\mathrm{Hr}$ batteries or $\mathrm{N}=3,4 \mathrm{~V}, 1 \mathrm{~A}$-hr batteries and so on. If however one desires to have $\mathrm{N}=5$, then $2.4 \mathrm{~V}, 1 \mathrm{~A}$-hr batteries would be needed. This arbitrary capacities are not commercially available and need to be designed for application specific purposes. One way to achieve this is to build cheap, biodegradable EDLC capacitors based on graphene and paper substrate which could replace $\mathrm{Pb}$-acid batteries. A comprehensive technological discussion on this topic is out of the scope of this paper, however an introductory comment will be made on use of supercapacitor as storage unit of modular storage system in later part of this section. Above mentioned design method is particularly suitable when the storage units are combined in series for discharging. But for charging, parallely connected storage units would provide opportunity to introduce faster charging schemes.

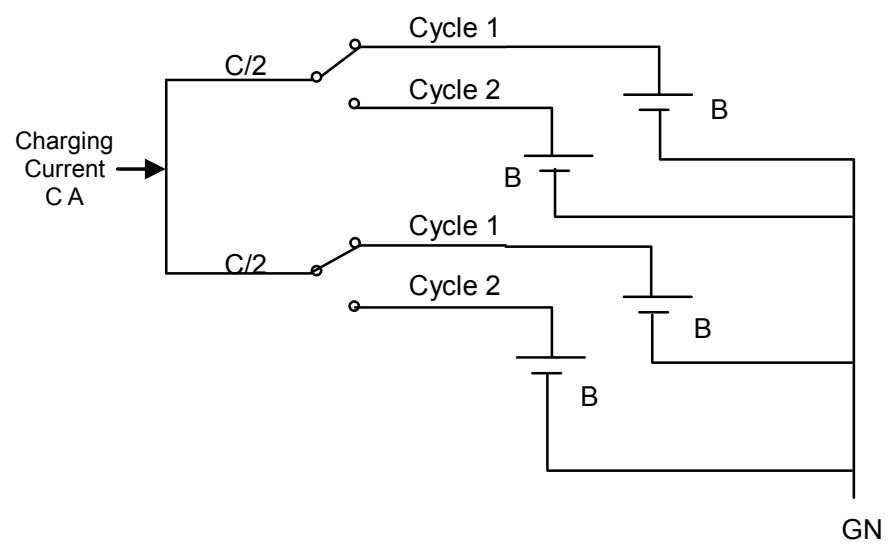

Fig. 5 Schematic of TDM charging of $\mathrm{N}=4$ modular storage system

$\mathrm{Pb}$-acid batteries can be charged using many different schemes. A typical charging scheme involves a initial constant current stage during which voltage increases close to $80 \%$ of maximum voltage rating [10]. Time required for $\sim 80 \%$ voltage depends upon charging current. Higher the charging current smaller is the duration of time. Typically $\mathrm{Pb}$-acid batteries are charged at $\mathrm{C} / 5 \mathrm{~A}$, for which 3 hours or more is required for $\sim 80 \%$ charging. At this rate full charge requires about 8 hours, implying that next $20 \%$ charging requires about more than $70 \%$ of the time. When charging current is $\mathrm{C} / 2 \mathrm{~A}$, charging could be completed under 3 hours. Charging $\mathrm{Pb}$-acid batteries above this rate may cause severe gassing, especially when voltage is greater than $90 \%$ of rated maximum voltage due to water electrolysis. 


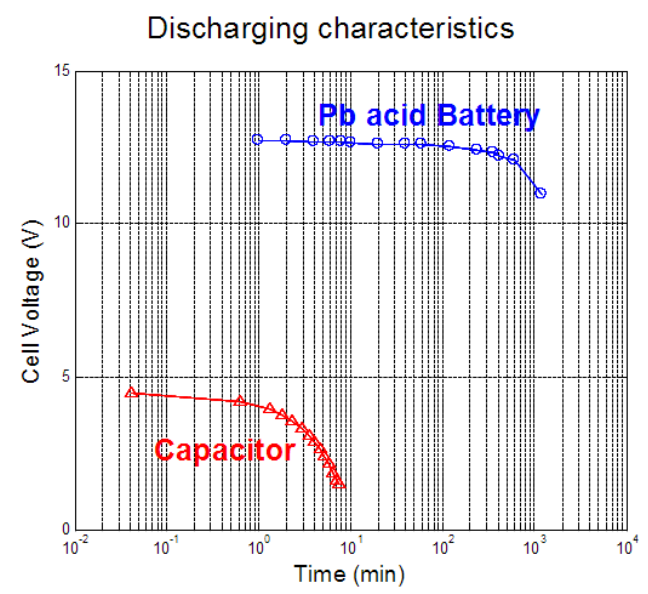

Fig. 6 Discharging characteristics of EDLC and PB-acid battery under similar discharging rate.

To keep gassing at low level and charge the batteries at relatively higher currents ( $\mathrm{C} / 2 \mathrm{~A}$ and above), pulsed charging can be used. In this paper, fixed width pulsed charging will be used to keep over all circuit cost to a minimum. Pulsed width modulation (PWM) charging scheme can also be adopted for modular storage system which is the most effective means to achieve constant voltage charging of a battery [10]. Thus for modular storage system with parallel charging connection and sequential charging at $\mathrm{C} / 2 \mathrm{~A}$ current, one could expect charging time of $3 \mathrm{~N}$ hrs. To reduce charging time, time-division multiplexed (TDM) charging needs to be introduced. For N=2, TDM charging scheme involves charging of two batteries alternatively; one is charged during first half of the pulse cycle and the other is charged during the second half of the pulse cycle (Fig. 4). Thus if the first battery is charged in $3 \mathrm{hrs}$, then the second one will be charged in $3+\mathrm{b}$ hrs. Total charging time is then expected to remain $\sim 3 \mathrm{hrs}$ if $\mathrm{b}<<3 \mathrm{hrs}$. For $\mathrm{N}=4$, charging should be done in groups of two batteries with each group being charged parallely using $\mathrm{C} / 2 \mathrm{~A}$ with total charging current of $\mathrm{C} \mathrm{A}$. In this case also charging time is $\sim 3$ hrs. Fig. 5 illustrates the TDM scheme of charging for $\mathrm{N}=4$ case. TDM can easily be extended to $\mathrm{N}>4$ cases. However for higher $\mathrm{N}$ systems limit will be set by charging power requirement and hence solar panel cost.

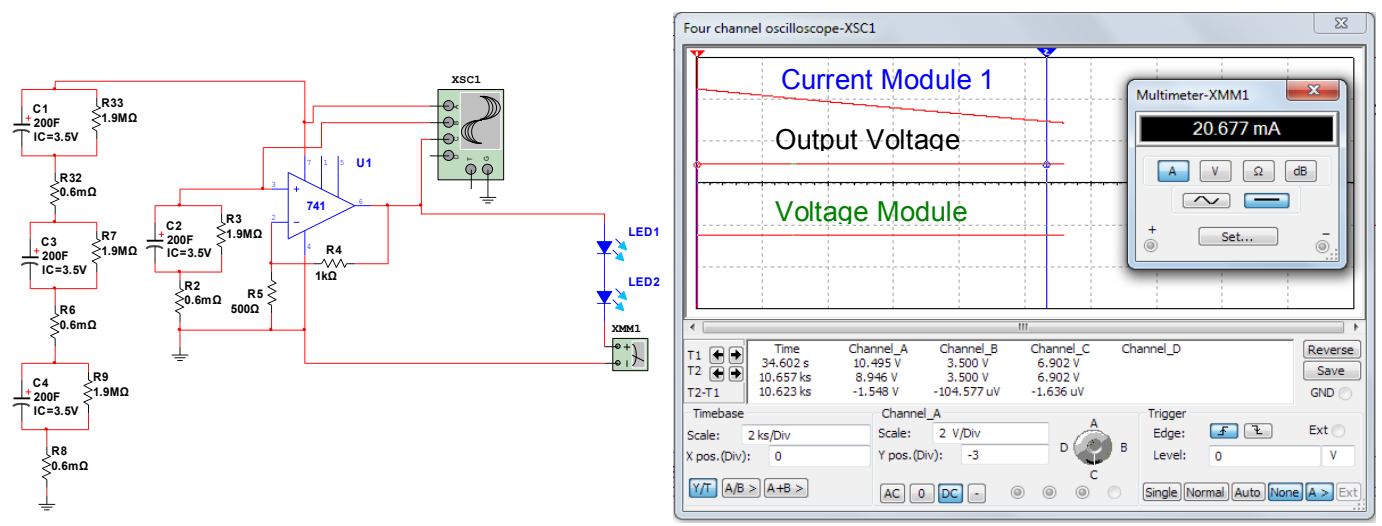

Fig. 7 EDLC based modular storage system showing constant output voltage.

As identified earlier electric double layer (EDLC) supercapacitors have many advantages over $\mathrm{Pb}$-acid batteries. However, EDLC also have disadvantages; particularly two important issues need to be resolved before they can be considered for modular storage system. First, shorter discharge cycle which could range from seconds to minutes and second, during discharge output voltage drops rapidly as compared to batteries. Fig. 6 shows comparison between discharging characteristics of ELDC and Pb-acid battery under similar discharge rate. This difference arises due to higher power density of EDLC as compared to Pb-acid batteries (Table 1). To 


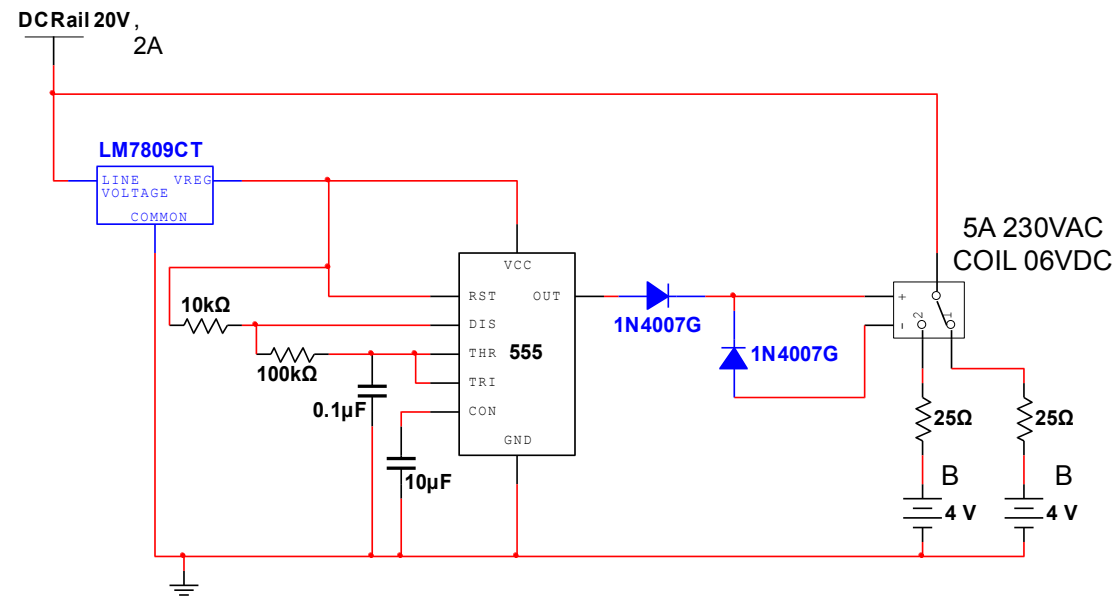

Fig. 8. Circuit implementation of TDM pulsed charging of two 4V, 1 A-hr batteries.

overcome these two issues the modular storage needs to be divided into two parts, one part should be able to keep a constant output voltage of the modular storage (voltage module) and other part should be able to provide desired current output (current module). A simple design to achieve this is shown in Fig. 7; where, current module1 is comprised of three EDLCs ( $\mathrm{C} 1, \mathrm{C} 3$ \& $\mathrm{C} 4)$, while the voltage module is made of one EDLC (C2). By adding number of current modules one could enhance lighting duration for such applications.

\section{TDM CHARGING OF PB-ACID BATTERY}

To demonstrate modular storage charging using TDM pulsed charging method, two $4 \mathrm{~V}, 1 \mathrm{~A}-\mathrm{Hr}$ sealed $\mathrm{Pb}$-acid batteries were chosen. A DC relay (GUARDIAN, 192 1C 06) was used for switching close to $1 \mathrm{~Hz}$ using a 555 timer (Fig. 8). This makes $\mathrm{b}=1 \mathrm{sec}$ and thus $\mathrm{b}<<3 \mathrm{hrs}$. Two current limiting resistors were used for controlling charging current. Fig. 9 shows typical pulsed charging characteristics of a single $\mathrm{Pb}$-acid battery with peak charging current at $\mathrm{C} / 10 \mathrm{~A}$. The total charging time for this case was $5 \mathrm{hrs}$ with output voltage at $4.02 \mathrm{~V}$ immediately after charging and $3.98 \mathrm{~V}$ after $30 \mathrm{~min}$ and $3.97 \mathrm{~V}$ after $24 \mathrm{hrs}$. Using TDM scheme two batteries could be charged in $2 \mathrm{hrs} 30 \mathrm{~min}$ at peak charging current of $\mathrm{C} / 2 \mathrm{~A}$. The series current limiting resistor

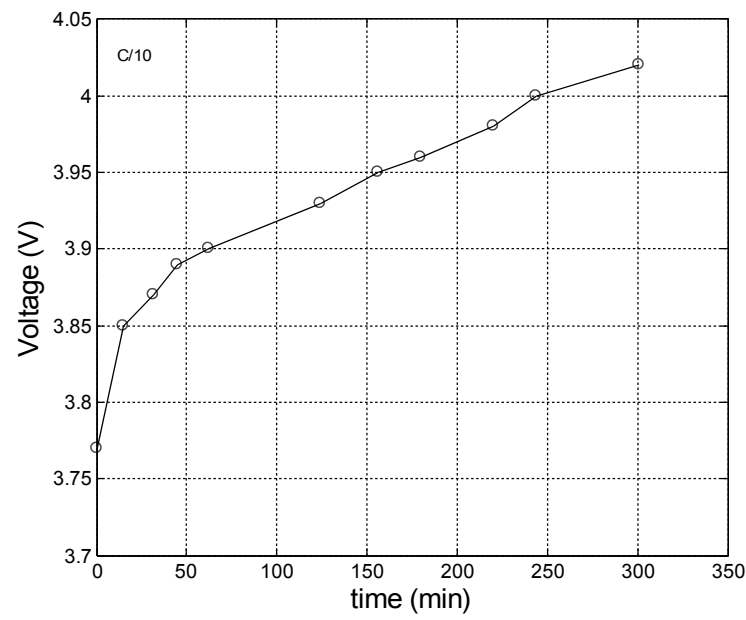

Fig. 9 Typical fixed width pulsed charging characteristics of $\mathrm{Pb}$-acid battery at $\mathrm{C} / 10 \mathrm{~A}$ peak charging current.

was of $25 \mathrm{Ohm}$, obtained from parallel connection four $100 \mathrm{Ohm}, 10 \mathrm{~W}$ resistors. The voltage levels, $30 \mathrm{~min}$ before and after charging was $2.95 \mathrm{~V} \& 4.17 \mathrm{~V}$ for battery B1 and $2.93 \mathrm{~V} \& 4.19 \mathrm{~V}$ for battery B2, respectively. Complete $3 \mathrm{hrs}$ charging lead to $4.22 \mathrm{~V}$ for both the batteries. Thus 12 volt modular Pb-acid storage with $1 \mathrm{~A}$-hr capacity can be charged in less than 3 hours using $\mathrm{C}$ A of input current. In this case average charging current for charging of 3 batteries will be $0.75 \mathrm{C} \mathrm{A}$. No heating and gassing was observed during the experiments. To decrease the charging power, the DC Rail voltage (Fig. 8) needs to be brought down. If DC rail specification is $5 \mathrm{~V}, 2 \mathrm{~A}$; to maintain the $\mathrm{C} / 2$ A peak charging current the current limiting resistor needs to be $2 \mathrm{Ohm}$ or less. 
Hence, in this case a 12 volt modular Pb-acid storage with $1 \mathrm{~A}$-hr capacity can be charged in less than 3 hours using $\mathrm{C} / 2 \mathrm{~A}$ peak charging current. The average charging power utilized in this case would be $3.75 \mathrm{~W}$. For a single $12 \mathrm{~V} 1 \mathrm{~A}$-hr battery, the charging power required would be $13 \mathrm{~W}$ for $\mathrm{C} / 2 \mathrm{~A}$ charging current and $13 \mathrm{~V} \mathrm{DC}$ Rail voltage. Hence it could be concluded that charging power required for a modular storage system would be far less than a single large storage system.

\section{Conclusion}

A new concept of modular electrical storage has been introduced which can be implemented using $\mathrm{Pb}$ acid battery or EDLC supercapacitors. This storage system can reduce the product cost by reducing the charging power requirement and distributing initial investment cost over time for solar off-grid applications. Experimental results show TDM pulsed charging can be used to charge a 12 volt modular $\mathrm{Pb}$-acid storage with 1 A-hr capacity in less than 3 hours $(2 \mathrm{hrs} 30 \mathrm{~min})$ using $\mathrm{C} / 2 \mathrm{~A}$ of peak charging current with out producing gassing and increasing temperature of the batteries. The average charging power required could be made as low as $3.75 \mathrm{~W}$ for such a system. Thus modular storage system is more energy efficient system than single large storage system.

\section{REFERENCES}

[1] V. Petrovic, Rapid battery charging method and Apparatus, US patent no. US 6388425 B1, 2001.

[2] M. Yilmaz, P. T. Krein, Review of Battery Charger Topologies, Charging Power Levels, and Infrastructure for Plug-In Electric and Hybrid Vehicles, IEEE Transactions on Power Electronics, 28(5), 2012, 2151-2169.

[3] S. R. Clarke, B-LAB: Changing the Game for Lead Acid, The Battcon 2011 Proceedings. Orlando, FL, 2011

[4] M. Oswal, J. Paul, R. Zhao, A comparative study of Lithium-Ion Batteries, University of South California, 2010.

[5] http://mahindrareva.com/product/specifications.aspx: Accessed June 2014.

[6] http://www.teslamotors.com/models/specs: Accessed June 2014.

[7] http://www.ioxus.com/ultracapacitors/: Accessed June 2014.

[8] B. Andres, S. Forsberg, A. P. Vilches, R. Zhang, H. Andersson, M. Hummelgård, J. Bäck - ström and H. Olin, Supercapacitors with graphene coated paper electrodes, Nordic Pulp and Paper Research Journal, 2012, 27 (2), pp. 481-485.

[9] M. Shoaib, V. Nagaraj, Novel Battery Charging Control System for Batteries Using On/Off and PWM Controllers for Stand Alone Power Systems, IOSR-JEEE, 6(3), 2013, 44-52.

[10] http://batteryuniversity.com/learn/article/charging_the_lead_acid_battery: Accessed June 2014. 